\title{
Editorial
}

\section{Making money from Antarctica}

$\mathrm{T}$ The Antarctic is no stranger to the economic opportunist. The history of whaling, sealing and now fishing shows that no place is too remote to deter industry exploiting the resources to meet a perceived market need. But all this has changed hasn't it? Antarctica today is a pristine wilderness 'devoted to peace and science' as it says in the Protocol. Maybe, but the climate in Antarctica is changing in ways other than meteorological so perhaps we should look more closely see what changes are brewing.

Fishing is now an established part of the economic exploitation of the waters around the Antarctic. Regulated through CCAMLR it is an industry always looking for new species and markets. With many of the other world fisheries heavily over-exploited the pressure on the Southern Ocean fisheries can only increase. Whilst most of the fishing effort has been north of $60^{\circ} \mathrm{S}$ so far, future exploitation may well extend into more southerly waters.

The last 20 years has seen a remarkable growth in a new industry-Antarctic tourism. With up to 10000 tourists visiting by ship and air each year there has been some concern both in scientific and Antarctic Treaty meetings that this must be causing considerable damage and needs specific legal controls. So far there is little rigorous proof of any significant damage to Antarctic ecosystems from these visits and the responsible tourist operators are trying to ensure it remains that way. Much more evidence exists of disruption to scientific research by visitors to research stations. Indeed, some stations in the Peninsula area have so many visitors they have employed guides specifically to deal with them. With increasing numbers of ship places and falling prices for the most popular cruises the pressure from this sector can only increase.

The history of tourism elsewhere in the world suggests that other activities will soon be requested - already there have been ski tours and mountaineering occurs every year. Soon there may be sky diving, SCUBA diving and even water skiing or golf competitions. Fertile imaginations in various countries are already generating new lucrative ideas including suggestions of hotels which, with their associated logistics and support systems, would take localized visitor impacts to new levels.

There are other, less obvious concerns. The chemical and pharmaceutical industry are forever searching the world for new compounds with valuable properties-perhaps anti-cancer drugs or anti-microbial compounds. Antarctic organisms may produce such compounds. Already one Australian company has purchased the right to screen a collection of Antarctic microbial isolates for active compounds. Researchers have published papers recognizing potentially interesting anti-microbial compounds manufactured by benthos. At present, if a useful substance is identified, what is to stop a major harvest of the organism responsible for making the compound being undertaken? Or, perhaps more likely, what is to stop the gene sequence responsible for producing the compound being identified, patented and commercially developed? There is no legislation to identify ownership or control over such activities as exists within sovereign boundaries for the rest of the world. Is Antarctic biodiversity there for anyone to exploit or should there be rules - as was suggested for any commercial exploitation of minerals?

Freedom of scientific investigation is the cornerstone of the Antarctic Treaty. In order to protect this freedom for the future, perhaps the scientific community should begin to consider more urgently if new limits need to be placed on some activities to prevent it being undercut by the uncontrolled exploitation of either Antarctic biodiversity or Antarctic wilderness properties.

D W H WaLTON 